\title{
Isolation and Cultivation of Some Pathogen Fungi from Apple and Grapevines Grown in Arges County
}

\author{
CAMELIA UNGUREANU ${ }^{1}$, MIRELA CALINESCU2*, MARIANA FERDES ${ }^{1}$, LILIANA SOARE ${ }^{3}$, DIANA VIZITIU4, IRINA FIERASCU5, \\ RADU CLAUDIU FIERASCU5, SILVIU RAILEANU ${ }^{1}$ \\ IUniversity Politehnica of Bucharest, 313 Splaiul Independentei Str., 060042, Bucharest, Romania \\ 2Research Institute for Fruit Growing Pitesti - Maracineni, 402, Marului Str., Arges, 110006, Romania \\ ${ }^{3}$ University of Pitesti, 1 Targul din Vale Str., 110040, Pitesti, Romania \\ ${ }^{4}$ National Research and Development Institute for Biotechnology in Horticulture Stefanesti Arges, 37 Bucharest - Pitesti Str., \\ 117715, Arges, Romania \\ ${ }^{5}$ The National Institute for Research \& Development in Chemistry and Petrochemistry, ICECHIM, 202 Spl. Independentei, \\ 060021, Bucharest, Romania
}

The development of apple and grapevines varieties displaying durable resistance against some disease is one of the major aims in breeding programmes worldwide. In order to test some bio fungicides, the isolation of some pathogens for apple (Podosphaera leucotricha, Venturia inaequalis) and grapevine (Plasmopara viticola) was carried out.

Keywords: Apple scab, powdery mildew, Podosphaera leucotricha, Plasmopara viticola, Venturia inaequalis

In a last decade, in modern agriculture, fungicides play a major role in maintaining crop health and reliable yields of agriculture products.

Recently, in Arges County, Romania, $45^{\circ} 0^{\prime} 0^{\prime \prime} \mathrm{N}$, $24^{\circ} 49^{\prime} 12^{\prime \prime}$, diseases occurring in fruit trees (apple, pear, peach, apricot, etc.) and vines are more common and very virulent than a few years ago. Explanations would be climate change that leads to increased rainfall, humidity and wind direction, but also to excess or unilateral application of nitrogen fertilizers. Also, the resistance of pathogenic germs to the multitude of synthetic treatments is a cause [1-2].

Plasmopara viticola (fam. Peronosporaceae, ord. Oomycetales, Cl. Phycomycetes) is the causal agent of grapevine downy mildew and was introduced into Europe in 1878; is considered as one of the most important grape pathogens worldwide [3]. Apple powdery mildew (APM) is a destructive pathogen, it produces damages in fruit and leaves.

Plasmopara viticola is the fungus, very common in our country, which can lead to production losses of up to even $80 \%$. As early as spring, resistance spores germinate at the surface of wet soil at temperatures above $10^{\circ} \mathrm{C}$ (the optimum being $23-24^{\circ} \mathrm{C}$ ) and from the inside a mycelian filament grows that falls on the ground. The spores thus formed arrive during the rains on the leaves (the inner part) where they penetrate the tissues of the plant producing the infection. At this moment yellow spots appear on the leaves because Plasmopara viticola begins the vegetative period in the leaf. The disease itself leads to the appearance of a white soft layer that carries the spores (viable for 7-8 days) and represents the mycelium. They penetrate the leaves through the stomata, being much better drained when they also have moisture from the rain. In autumn the secondary contamination occurs when the cycle closes, forming again resistant spores which germinate again in the spring. It is very important to drain the soils that strongly retain the water and destroy the leaves and grass around the plantations and / or realize deep excavations.

Fruits can be attacked after they reach a surface of 10 $25 \mathrm{~cm}^{2}$ until they get old and have various aspects starting from a yellow aspect in spring to a brown aspect in autumn (dryand burned aspect). On the back of the leaves appears a whitish layer representing the fungus mycelium and spores. The attack on sprouts manifests itself through the appearance of some brown spots that during rainy weather is covered with a whitish layer composed of mycelium spores. The vine strings thus attacked no longer reach maturity. In the very rainy years, young resins suffer the most and lead to dramatic decline in production. During autumn, Plasmopara viticola, forms resistance organs that germinate again in spring [4-6].

Podosphaera leucotricha f.c oidium farinosum is the fungus responsible with the powdery mildew disease. This disease occurs from debuding and continues until leaves fall during autumn, with an increased progression in MayJune. In the mildew case flowers, leaves, sprouts and even young fruits are affected. The disease manifests itself in the form of a whitish flour (dust) covering all the above listed categories and leads to their early drying. Podosphaera leucotricha covers the sprouts with a whitish mycelium layer in the form of powder / flour when the spores are formed and in autumn this powder becomes brown at the time of fungus fructification. The most sensible variety of apple which is exposed to the mildew process is the J onathan on whose leaves appears a fine mesh of brown tissue. In winter, this pathogen in the form of a resistance mycelium grows between the scales of spring buds that form sprouts, leaves, flowers that are the first sources of infection. Thus, as the first prevention and control measure, it is recommended that the severely affected sprouts be cut and destroyed by burning [7-8].

In addition to powdery mildew disease, the apple scab disease is also a very aggressive disease that attacks apple species. Venturia inaequalis is the microorganism responsible for this disease that attacks all the aerial parts of the tree, especially leaves and fruits. On leaves it appears on their backs in the form of gray spots that become brown as they grow and on flowers it appears on sepals. On the fruit appear the same gray spots that can grow and are gateways for other diseases and microorganisms. A scab resistant apple breed is the Florina species [9-10].

Due to of multiple benefits for human health [11], disease prevention of apple has attracted significant attention in the scientific field.

*email: elacalinescu@yahoo.com; Phone:+40721640727 
Horticultural wild plants are genetically more diverse and produce a range of bioproducts (e.g. bio fungicides) that are of considerable value to reduce biocenotic stress in horticultural crops [12]. In order to test some bio fungicides, the isolation of some pathogens for apple (Podosphaera leucotricha, Venturia inaequalis) and grapevine (Plasmopara viticola) was carried out.

\section{Experimental part}

Materials and methods

The isolation of Podosphaera leucotricha and Venturia inaequalis was performed on Starkrimson Red Delicious Apple (species sensitive to these diseases).

Experiences were effectuated with samples (fruits and leaves) from Research Institute for Fruit Growing PitestiMaracineni (apple) and National Research and Development Institute for Biotechnology in Horticulture Stefanesti Arges (grapevines), Arges County.

The environmental conditions have a major role in the disease epidemics butalso the biological reserve. The mean daily temperature, relative air humidity and cumulative rainfall was recorded at the meteorological station (iMetos). During 01.03.2018-23.07.2018 was recording 453 $\mathrm{mm}$ of precipitation (average precipitation ranges).

\section{Fungal isolation}

Fungal strains were cultivated onto potato-dextrose agar (abbreviated PDA) from Sigma-Aldrich with next composition: agar, $15 \mathrm{~g} / \mathrm{L}$, dextrose, $20 \mathrm{~g} / \mathrm{L}$ and potato extract, $4 \mathrm{~g} / \mathrm{L}$ supplemented with $0.1 \mathrm{~g} / \mathrm{L}$ chloramphenicol. Chloramphenicol antibiotic was used to avoid the bacterial contamination.

Leaf and fruits pieces containing lesions were made into small pieces (with sterile razor blade) and placed on the PDA medium in Petri dishes at $22-24^{\circ} \mathrm{C}$ for $4-5$ days [ 8 , 20] in aseptic conditions. Aseptic conditions involve the sterilization of media, glassware, and tools before use as well as measures to prevent contamination by contact with non-sterile objects.

After incubation, colonies of different shape and colors were observed on the plates. A pure culture of each colony type on each plate was obtained and cultivated.

Morphological observations were taken based on colony, conidia and conidiophore morphology and other morphological characters (e.g. sporangiospores, mycelium, spores) [13-14]. For fungal slide mounts was use tape touch method. Tape touch method is simply and widely used method for staining of fungus [15]. Briefly, to prepare a mount, is taken a tape ûag by the applicator stick handle and is touched the tape to a fungal colony in a culture dish opened in a clean room. The tape ûag with attached fungal elements from the colony is put onto a drop of mounting medium (lactophenol) on a cover glass. The investigation was effectuated with an Epifluorescent Microscope FLUO 3 light microscope, Bel Capture Software.

\section{Results and discussions}

Pow dery mildew of apple occurs in apple of all regions and causes economic damage by reducing flower bud production, and fruitquality. Figure 1 presents the symptoms on powdery leaves and fruits caused by Podosphaera leucotricha.

Leaves and fruits were transferred into the laboratory and then the fungi isolated from diseased fruits and leaves (see Chapter Materials and methods). Figure 2 represents stages of powdery mildew isolation (direct plating of fungal leaves on PDA media).

Apple scab is a complex disease caused by Venturia inaequalis that develops following phases: a monocyclic phase caused by ascospores produced in pseudothecia originating from leaf lesion present the previous fall; apple scab occurs wherever apples are grown and may be a very serious disease on susceptible varieties. This disease, caused by the fungus may be quite severe when rainy,
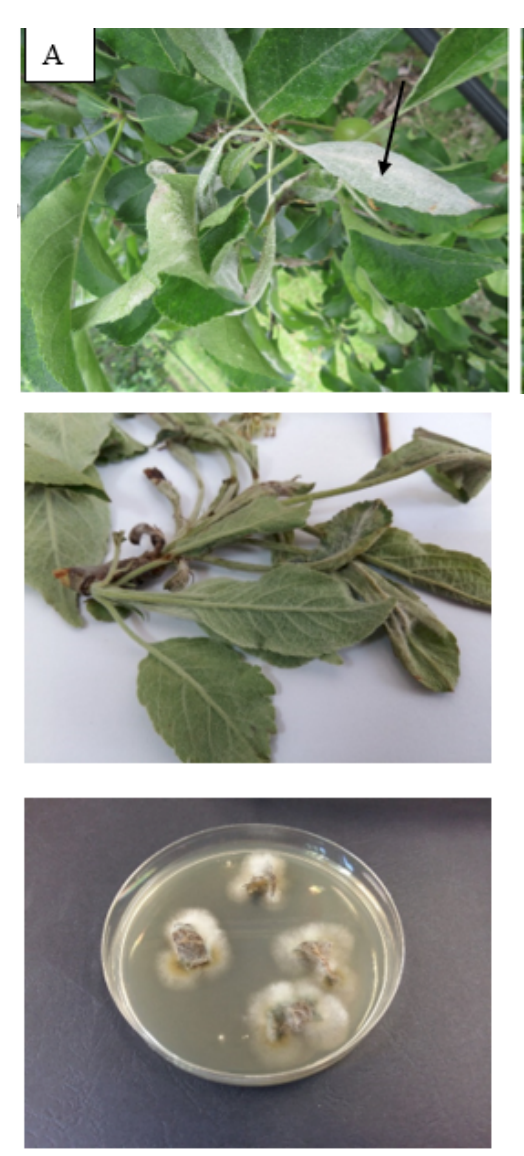

Fig. 1 Symptoms on powdery mildew leaves and fruits caused by Podosphaera leucotricha: well-developed lesions on fruits and leaves (A); lesions on leaves (B)

Fig. 2 Stages of powdery mildew isolation 

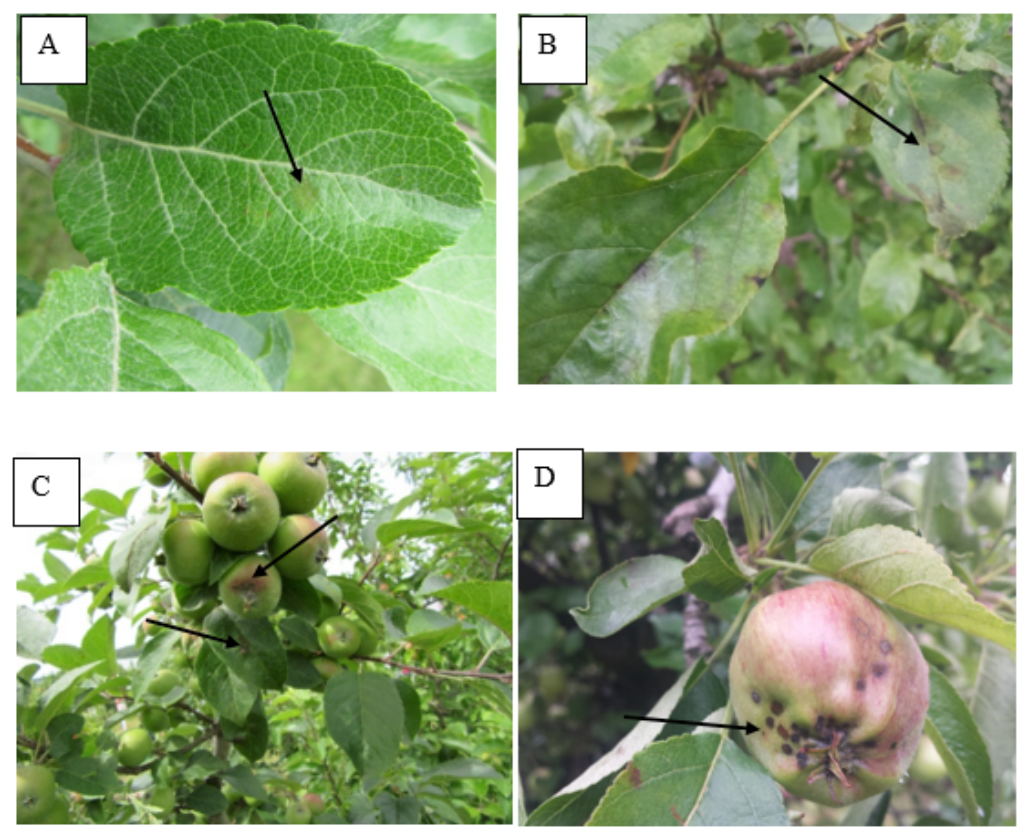

cool weather occurs in the spring. The installation and rapid evolution of the apple scab is conditioned by temperatures above $7^{\circ} \mathrm{C}$ and water on leafs for a period of over 9 hours.

Figure 3 presents the, some symptoms on apple leaves and fruits caused by Venturia inaequalis.

Stages of apple scab isolation is presented in Figure 4.

In grapevine, the penetration and sporulation of Plasmopara viticolaoccurvia stomata. The vineyard does not form under dry conditions. Microconiidies under favorable conditions, i.e. in raindrops or dew germinate within 2-9 hours after their formation. The germination duration of the microconidia is one hour, so it takes a heavy rain or dew to
Fig. 3 Symptoms on apple leaves and fruits caused by Venturia inaequalis: newly developed lesions on apple leaves (A); well-developed lesions on leaves (B); lesions on fruit and leaves $(C)$; fruit deformation caused by early infections (D)
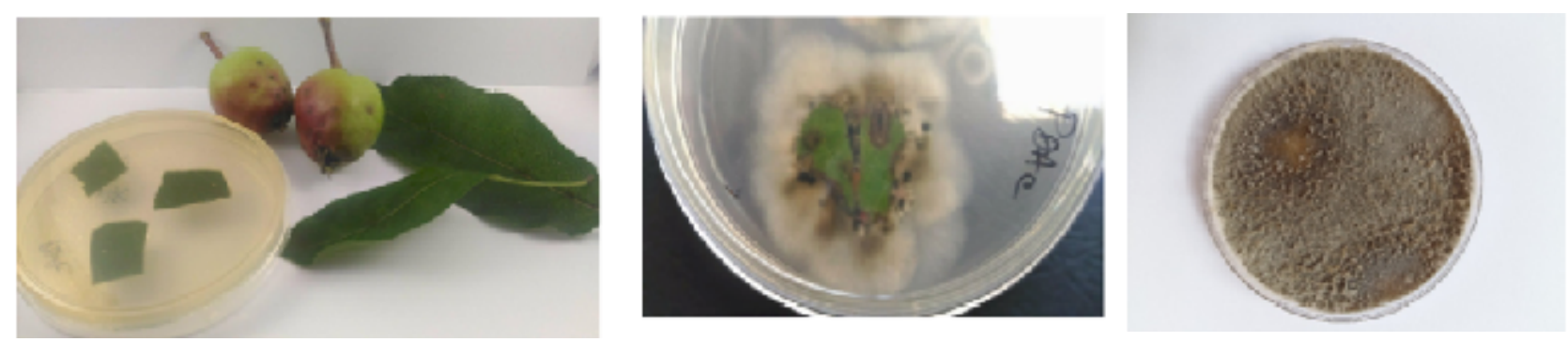

Fig. 4 Stages of apple scab isolation
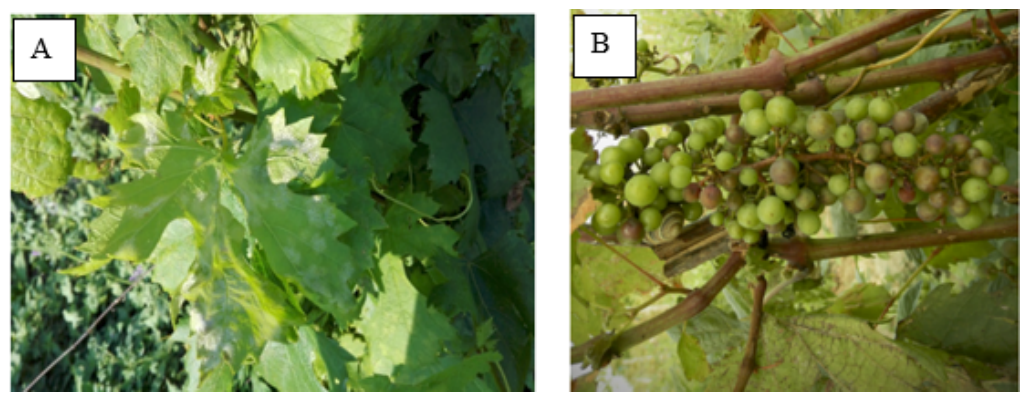

Fig. 5 Symptoms on vineyard leaves and fruits caused by Plasmopara viticola (A); lesions on leaves $(B)$ lesions on fruits
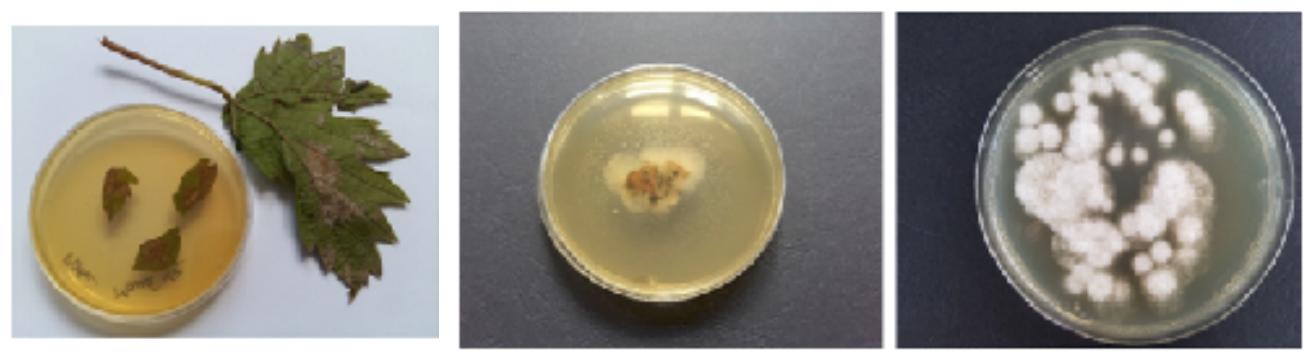

Fig. 6 Stages of Plasmopara viticola isolation 

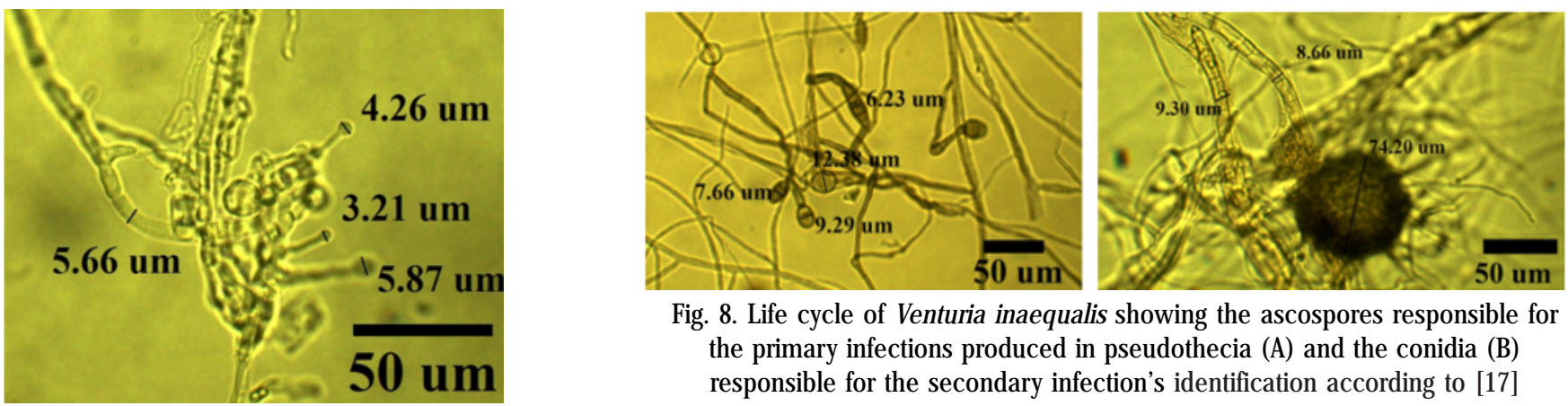

Fig. 8. Life cycle of Venturia inaequalis showing the ascospores responsible for the primary infections produced in pseudothecia (A) and the conidia (B) responsible for the secondary infection's identification according to [17]

Fig. 7 Conidiophore and emerging asexual conidia, Podosphaera leucotricha - microscope

view, identification according to $[8,16]$

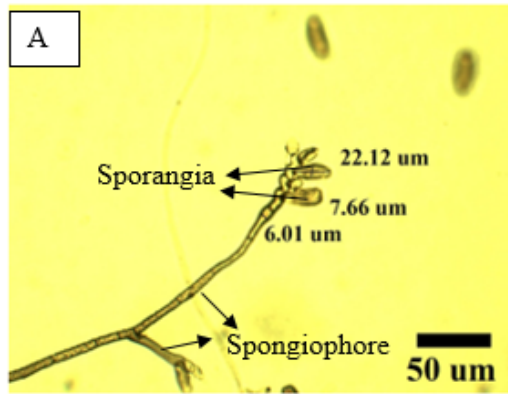

almost exclusively asexually, although ascospores might be an underrated additional source of infection $[8,16]$.

Life cycle of Venturia inaequalisshowing the ascospores responsible for the primary infections produced in pseudothecia (Figure 8, A) and the conidia (Figure 8, B) responsible for the secondary infections. The fruiting bodies, ascocarps appear in the form of pseudothecia. A pseudothecium has small dark hairs around its opening and contains pseudoparaphyses along with asci [17].

The asci (brown) are elongated, sac-like structures, each of which contains eight unequal bicellular ascospores in a linear arrangement (hence the name of the species inaequalis), 6-13 $\mu \mathrm{m}$ wide and 11-15 $\mu \mathrm{m}$ in length. These are carried by the wind and the rainfall causing the infections during the vegetation period.

A polycyclic phase (secondary infections) produced by conidia originating from lesion on leave and fruits occurs in the vegetation period at the surface of the spots, in the form of conidiophores containing conidia (spores). Conidia (Figure $8 \mathrm{~B}$ ) are made up of a single, brown and pyriform cell, with a width between 6-12 $\mu \mathrm{m}$ and the length between $12-22 u \mathrm{~m}$

Microscope view for Plasmopara viticola revealed a high number of sporangiophores, sporangia and stomata conforming other studies [18-19]. Stomata also constitute natural openings providing direct access to leaf tissue for $P$. viticola (fig. 9). This process is realized in a proportion of $90-100 \%$ on the lower side of the leaves.

\section{Conclusions}

In order to test some bio fungicides, the isolation of some pathogens for apple (Podosphaera leucotricha, Venturia inaequalis) and grapevine (Plasmopara viticola) was carried out

Experiences were effectuated with samples (fruits and leaves) from Research Institute for Fruit Growing Pitesti Mãrãcineni (apple) and National Research and Development Institute for Biotechnology in Horticulture Stefanesti Arges (grapevines), Arges County.

Acknowledgement: This work was supported by a grant of the Romanian Ministery of Research and Innovation, CCCDI-UEFISCDI,
Fig. 9 Plasmopara viticola (microscope view) - A, B Sporangiophores and sporangia,identification according to $[18,19]$

\section{PCCDI/2018, within PNCDI II}

\section{References}

1. GIRAUD, T., GLADIEUX, P., GAVRILETS, S., Trends in Ecology and Evolution, 25, 2010, p. 387- 395.

2. AGRIOS, G., Plant Pathology. 5th Edition, Elsevier Academic Press, Amsterdam, 26-27, 2005, p. 451.

3. WONG, F.P., BURR, H.N., WILCOX, W.F., Plant Pathology, 50, 2001, p. 427.

4. Mac HARDY, W.E., Epidemiology, and Management. St. Paul, Minn, USA, APS., 1996, p. 25

5. THAKUR, V.S., SHARMA, R.D., Diseases of Horticultural Crops-Fruits, Indus Publication Co. New Delhi, 1999, p. 15.

6. YIN, X., LIU, R., SU, H., SU, L., GUO, Y. et al. Horticulture Research, 4, 2017, p. 17033

7. ADASKAVEG, J., GLUBER, D., MICHAILIDES, T., HOLTZ, B., UC Statewide IPM Program, 2010

8. URBANIETZ, A., and DUNEMANN, F., Plant Pathology, Wiley Online Library, 2005

9. GONZALEZ-DOMINGUEZ, E, ARMENGOL, J., ROSSI, V., Frontiers in Plant Science, 8, 2017

10. KOHL, J., de HAAS, B.H, MOLHOEK, W.M.L., Proceeding from European J oint Organic Congress, 30-31 May, Odense, Denmark, 2006, p. $354-355$

11. Ploscutanu, G., Elisei, A. M., BuZiA, O. D., Rev. Chim. (Bucharest), 70, nr. 3, 2019, p. 934

12. SUTAN, N.A., FIERASCU, I., FIERASCU, R.C., MANOLESCU, D.S., SOARE, L.C. Industrial Crops and Products, 2016, 83C, p. 379.

13. LESLIE, J.F., SUMMERELL, B.A. Blackwell Publishing. First edition, 2006, p. 388.

14. SIMMONS, E.G., CBS Fungal Biodiversity Center Utrecht the Netherlands, 2007, p. 775.

15. HARRIS, J. L., J ournal of Clinical Microbiology, 2000, 38, nr. 12, p. 4683.

16. JAKAB-ILYEFALVI, Z. Annals of the Romanian Society for Cell Biology, 2016, 20, nr. 2, p. 15.

17. DEWDNEY, M. CARISSE, O. Phytoprotection. 2002, 83, nr. 1, p. 1.

18. YIN, X., LIU, R. et al. Hortic. Res., 2017, 4, p. 17033.

19. RUMBOLZ, J., WIRTZ, S., KASSEMEYER, H. -., GUGGENHEIM, R., SCHÄFER, E., \& BUCHE, C. Plant Biology, 2002, 4, nr. 3, p. 413.

20. MANE M. A., BODKE S. S., DHAWALE R. N. Int. J. Curr. Microbiol. App. Sci, 2018, 6, p. 714

Manuscript received: 19.04 .2019 